\title{
The Effects of Sandplay Therapy on Depression and Stress from Child Rearing in Mothers with Disabled Children
}

Kyunghee Kim*

\author{
Songhee $\operatorname{Han}^{* *}$
}

\begin{abstract}
$<$ Abstract $>$
This study applied sandplay therapy to mothers with disabled children and had them express emotions suppressed while rearing their children, thereby intending to improve their power to cope with stress through internal reinforcement that may relieve psychological recession. In order to verify the above study issues, 28 mothers were selected as subjects and equally divided into an experimental group and a control group. The experimental group received sandplay therapy for 40 minutes once per week, for a total of 10 weeks, and a test on the scale of depression and stress from child rearing was conducted prior to and after each session of sandplay therapy. The results of this study showed that sandplay therapy was effective in decreasing depression and stress from child rearing in mothers with disabled children. This study's results are considered to provide basic data that can be utilized as a psychological therapeutic approach for seeking the stability of depressed ego resulting from depression and stress in mothers with disabled children, and also improvement in the quality of care of disabled children.
\end{abstract}

Keywords : sandplay therapy, depression, stress from child rearing

\footnotetext{
* Professor, Department of Consulting and Psychology, Digital Seoul Culture Arts University (p30kkh@scau.ac.kr)

** Play therapist, BOMNC Development Center for Children and Youth (gemini0235@naver.com)
} 
Journal of Symbols \& Sandplay Therapy, Vol.7 No.2.

\section{I . Introduction}

\section{Research Objective and Necessity}

Family is the starting point for a new life that one forms together with his or her lifelong partner (Jeong, 2008). Once a man and a woman form a family through marriage, they often have children and become parents. Parents play a pivotal role in forming children's initial relationships. The presence of a child can be positive for the parents, as they attain both psychological and social stability, develop new interests through their interaction with the child, and are given the opportunity to reflect on their lives through parenting. At the same time, however, parents are faced with various burdens and stresses related to child rearing, some of which include lack of personal time and increased mental and physical fatigue due to increased expenditure (Lee, 2008)

Although all parents face hardships of parenting, the hardships that families with disabled children undergo are incomparable to the ones experienced by those with nondisabled children. Because a disability cannot be cured immediate through treatment or counseling, parents with disabled children more often than not experience psychological depression and distress and are constantly under an enormous amount of pressure rather than a sense of achievement and anticipation (Lee, 2008).

Being the primary caretaker of the disabled children in the family, mothers are often overburdened, which facilitates depression and parenting stress (Lee, 2005). With the birth of a disabled child, mothers experience a range of negative emotions: a sense of loss, anger, shock, denial, sadness and dejection (Seo, Jang, Jeong \& Choi, 2003). Because information about the attributes of disabled children and ways to nurture them is not easily accessible, mothers have a hard time understanding the nature of the disability and lose confidence about their child rearing ability (Kim, 2011). And from the thought that their children can never become complete stems emotions like sadness, anger, guilt and self-condemnation (Kanner, 1953).

Another reason for these mothers' high level of depression is the uncertain future of their children (Hong \& Kim, 2003). Through child-rearing, mothers with disabled children face 
frustration, burdens and feelings of restraint as well as suffer from physical fatigue and psychological wounding, thereby becoming depressed (Choi, 2007). Mothers are often obliged to invest a significant amount of time in taking care of the disabled children; almost all daily activities of these children are conducted under the assistance of the mother. Disabled children require special attention and are dependent on their mothers for almost all their lives. The mothers bear full responsibility of the care (Lee \& Hwang, 2015). The mothers are also constantly under physical and psychological stress due to lack of time for sleep and leisure because these children need intensive guidance and protection (Lim, 2004; Baek, 2009).

In addition, these mothers experience constant parenting stress because it is difficult to know how to cope with problem behaviors that are commonly seen in disabled children (Jeon, 2006). Moreover, these mothers continuously must fight the social prejudice against disabled children. They experience high levels of parenting stress as they experience frustrations and unrealistic expectations for children with disabilities. These stresses make mothers to feel depressed, and depressed mothers display negative parenting behaviors, which causes the mothers to feel further stressed when taking care of their children (Kim \& Kim, 2010). In other words, depression and parenting stress of mother of disabled children have a significant positive correlation. Depression and parenting stress significantly reduce the quality of care (Jeong \& Kim, 2011), make daily life difficult, and adversely affect family adjustment, all of which hinder the systematic functioning of a family (Lee, 2008).

With greater impact of disabled children on the family and greater emphasis on the role of the mothers in rearing disabled children, many studies have been done on mothers' depression and stress stemming from their children's disability. A study on the relationship between social support and depression in mothers with disabled children have proven that these mothers experience a high level of depression (Hong \& Kim, 2003). A study on the relationship between parenting stress and depression in mothers with disabled children focusing on social support reported that these mothers have a high level of depression and stress (Lee, 2000). A number of theoretical approaches have discovered that depression and parenting stress in mothers with disabled children has a negative impact on child rearing and family functioning. Based on these findings, sandplay therapy was employed in related studies. The 
Journal of Symbols \& Sandplay Therapy, Vol.7 No.2.

study of Kim (2014) found sandplay therapy reduces depression in mothers with disabled adolescent children and improved the mother-child relationship. The study of Shin (2006) found that the changes the mothers underwent after sandplay therapy positively affected children's self-esteem in terms of the House-Tree-Person test. Results of other studies showed that sandplay therapy increased the mothers' positive verbal expression quantitatively and helped them to develop a more accepting attitude toward others and their environment (Park, 2008; Han, 2009).

Mothers with disabled children feel guilty and depressed about their children's disability. Touching sand in sandplay therapy reduces anxiety and provides therapeutic regression, eases tension, and brings about psychological and emotional stability (Shim, 1994). The positive act of creating a world in sandtray allows mothers of disabled children experiencing parenting stress to express their negative emotions. Through a natural regression in the safe world of sandtray, mothers face repressed needs and emotions, which are their shadows in the unconscious. And through a stable, supportive relationship with the therapist, they have the opportunity to become more mature in terms of being able to gain an objective insight into their depression and stress. This opportunity for self-maturity will be an emotional basis that would enable the mothers to manifest the energy for child rearing. In other words, sandplay therapy can help mothers develop the ability to cope with parenting stress: That is, they will be able to interpret and accept their life in a positive manner as individuals (Park, 2008).

This study provided sandplay therapy to mothers of disabled children to help them express their repressed emotions and to strengthen their inner worlds, which can reduce psychological depression and thereby improve their stress-coping ability. Plus, the study sought to confirm whether sandplay therapy process reduces depression and parenting stress in mothers of disabled children through a quantitative analysis. This study is expected to provide basic data that can be utilized as a psychological therapeutic approach for seeking the stability of depressed ego-resulting from depression and stress-in mothers with disabled children, and for improving quality of care for disabled children. 


\section{Research Questions}

This study asked the following questions in order to apprehend the influence of sandplay on the depression and child-rearing stress of mothers with disabled children:

1. Can sandplay therapy reduce depression in mothers with disabled children?

2. Can sandplay therapy reduce parenting stress in mothers with disabled children?

\section{ПI. Research method}

\section{Participants}

This study recruited 28 mothers of disabled children who experienced difficulty in life due to depression and parenting stress. Participants either volunteered or were recommend by faculty members of a child development center or the Rehabilitation Association for the Disabled in the city of Daejeon. With the participants' prior consent, the researchers measured the level of both depression and parenting stress tests in those 28 mothers. Among them, 14 mothers who voluntarily agreed to participate in sandplay therapy were assigned to the experiential group, and the remaining 14 were assigned to the control group. The demographic characteristics of the participant are shown in Table 1.

There were no significant differences between the experiential group and the control group in terms of the children's gender, age, type of disability, degree of disability, birth order as well as the mothers' academic career and occupation.

\section{Tools}

\section{1) Depression scale: Beck Depression Inventory}

The study referred to the Beck Depression Inventory (BDI) to measure the level of depression in mothers. The BDI is a self-report inventory that was developed with a view to 
Journal of Symbols \& Sandplay Therapy, Vol.7 No.2.

Table 1. A comparison of participants' characteristics

\begin{tabular}{|c|c|c|c|c|c|c|}
\hline & & \multicolumn{2}{|c|}{$\begin{array}{l}\text { Experimental group } \\
\qquad(\mathrm{n}=14)\end{array}$} & \multicolumn{2}{|c|}{$\begin{array}{l}\text { Control group } \\
\quad(n=14)\end{array}$} & \multirow[t]{2}{*}{$x^{2}$} \\
\hline & & $\mathrm{n}$ & $(\%)$ & $\mathrm{n}$ & $(\%)$ & \\
\hline \multirow{2}{*}{ Child's gender } & Male & 9 & $(64.3)$ & 8 & $(57.1)$ & \multirow{2}{*}{.150} \\
\hline & Female & 5 & $(35.7)$ & 6 & $(42.9)$ & \\
\hline \multirow{6}{*}{ Child's age } & 8 (Grade 1) & 1 & (7.1) & 1 & (7.1) & \multirow{6}{*}{.343} \\
\hline & 9 (Grade 2) & 1 & (7.1) & 1 & $(7.1)$ & \\
\hline & 10 (Grade 3) & 2 & $(14.3)$ & 3 & $(21.4)$ & \\
\hline & 11 (Grade 4) & 1 & (7.1) & 1 & $(7.1)$ & \\
\hline & 12 (Grade 5) & 4 & $(28.6)$ & 3 & $(21.4)$ & \\
\hline & 13 (Grade 6) & 5 & $(35.7)$ & 5 & $(35.7)$ & \\
\hline \multirow{3}{*}{ Child's disability } & Autism & 3 & $(21.4)$ & 3 & $(21.4)$ & \multirow{3}{*}{.000} \\
\hline & Intellectual disability & 10 & $(71.4)$ & 10 & $(71.4)$ & \\
\hline & Brain lesions & 1 & (7.1) & 1 & (7.1) & \\
\hline \multirow{3}{*}{ Degree of disability } & Mild & 5 & $(35.7)$ & 6 & $(42.9)$ & \multirow{3}{*}{.182} \\
\hline & Moderate & 6 & $(42.9)$ & 5 & $(35.7)$ & \\
\hline & Severe & 3 & $(21.4)$ & 3 & $(21.4)$ & \\
\hline \multirow{3}{*}{ Child's birth order } & Only child & 1 & (7.1) & 5 & $(35.7)$ & \multirow{3}{*}{4.000} \\
\hline & First child & 8 & $(57.1)$ & 4 & $(28.6)$ & \\
\hline & Second child & 5 & $(35.7)$ & 5 & $(35.7)$ & \\
\hline \multirow{3}{*}{$\begin{array}{c}\text { Mother's } \\
\text { academic career }\end{array}$} & High school graduate & 8 & $(57.1)$ & 6 & $(42.9)$ & \multirow{3}{*}{1.486} \\
\hline & Junior college graduate & 3 & $(21.4)$ & 6 & $(42.9)$ & \\
\hline & University graduate & 3 & $(21.4)$ & 2 & $(14.3)$ & \\
\hline \multirow{2}{*}{$\begin{array}{l}\text { Mother's } \\
\text { occupation }\end{array}$} & Stay at home & 10 & $(71.4)$ & 8 & $(57.1)$ & \multirow{2}{*}{.622} \\
\hline & Working & 4 & $(28.6)$ & 6 & $(42.9)$ & \\
\hline \multicolumn{2}{|c|}{ Total } & 14 & $(100.0)$ & 14 & $(100.0)$ & \\
\hline
\end{tabular}

assessing the existence of depression symptoms and their severity (Beck, 1976). To be more precise, the scale implemented in this study was a BDI variation adapted by Lee Young-ho and Song Jong-yong in Korea (1991). The scale is comprised of 21 items related to emotional, 
cognitive and physical depression symptoms. Responses are rated on a 3-point scale and range from 0 to 63 , with higher scores indicating greater depressive symptoms. Here depression includes emotional (sadness, pessimism, crying, dissatisfaction, guilt), cognitive (feelings of failure, punishment, indecisiveness, self-hate, self-criticism, suicidal thought), motivational (physical disability, occupational disability, hypersensitivity, social withdrawal, insomnia), and physiological factors (fatigue, weight loss, appetite loss, physical obsession). Scores are interpreted as follows: 0-9 indicates the normal range, 10-15 indicates mild depression, 16-23 indicates moderate depression, and 24-63 indicates severe depression. The Cronbach's alpha of the BDI is .85 .

\section{2) Parenting stress scale: Parenting Stress Index/Short Form}

To measure the parenting stress of mothers with disabled children, the study used the Parenting Stress Index/Short Form, or the PSI/SF. The original version of the index, the Parenting Stress Index, was created by Richard R. Abidin (1983) and has a total of 101 items. However, Hye-young Seo in 1992 created a shorter version of this index comprised of 36 items, which are divided into three subscales.

The three subscales of PSI/SF are the three major domains of stressor source: parental distress, parent-child dysfunctional interaction, and difficult child. The "parental distress" domain deals with problems related to parental depression, lack of social support, conflict with spouse, limitation of role, impairment of parenting ability, and adaptation problem that causes dysfunctional parenting. The "parent-child dysfunctional interaction" domain deals with parental acceptance, the strengthening of the child to the parent, parent's affection toward the child, and the interaction with the child is. The "difficult child" domain deals with the child's temperament, child's rebellious behavior, and the learning patterns of the required behavior.

The items were scored with a five-point Likert scale $(1=$ Totally disagree, $5=$ Totally agree), Scores range from 36 to 180, with higher scores indicating greater parenting stress. The following scores indicate severe stress: 36 or more in the parental distress domain, 27 or more in the parent-child dysfunctional interaction domain, and 36 or more in the difficult child domain. Cronbach's alpha for all the items is .83 . 
Journal of Symbols \& Sandplay Therapy, Vol.7 No.2.

\section{Design and Procedure}

This study adopted a pretest-posttest design for the purpose of examining the effects of sandplay therapy on depression and parenting stress in mothers with disabled children

A total of 10 weekly sandplay sessions were conducted for three months, from April 2015 to June 2015. After each therapy, the sandplayer had a 40-minute individual counseling session. A self-report depression scale and a self-report parenting stress scale were carried out before and after therapy. Prior to the therapy, all participants agreed to have the contents of their therapy voice-recorded and videotaped. Sandplay therapy was unstructured and non-directive, where the participants created their own sandpictures without being given a specific theme. The researchers participated in the therapy as an observer.

The sandtray was placed on a desk in front of the client. The figure shelf was placed either to the left or right of the client. The figures on the shelf were organized into different categories: humans, houses, buildings, transportations, animals, insects, animation characters, death-related objects, nature-related objects, indicators of connection and separation, and archetypal symbols.

\section{Data Collection and Analysis}

Collected data was analyzed in the following manner using the Statistical Package for Social Science (SPSS) 18.0: Frequency and percentage were calculated to compare the general qualities between mothers of the experimental group and mothers of the control group, after which a chi-squared test was used. Next, an independent t-test was run on the data for a homogeneity test of the pretest depression level and pretest parenting stress level in both groups. Lastly, the pretest results were used as covariates to carry out an analysis of covariance (ANCOVA) in order to observe the impact of sandplay therapy on the mothers' depression and parenting stress. 


\section{Results}

1. Can Sandplay Therapy Reduce Depression in Mothers with Disabled Children?

This study first carried out a homogeneity test of the pretest depression level for both the experimental group and the control group in order to answer the first research question: "Can sandplay therapy reduce depression in mothers with disabled children?" As seen in Table 2, the pretest depression level of the experimental group $(M=19.71)$ was higher than that of the control group $(M=15.14)$, the difference of which was statistically significant $(t=2.17$, $\mathrm{p}<.05)$. Therefore, the pretest depression levels of the experimental group and the control group were not homogeneous.

Table 2. Homogeneity test: pretest depression level of the experimental group and the control group

\begin{tabular}{|c|c|c|c|c|c|}
\hline & \multicolumn{2}{|c|}{$\begin{array}{l}\text { Experimental group } \\
\qquad(\mathrm{n}=14)\end{array}$} & \multicolumn{2}{|c|}{$\begin{array}{l}\text { Control group } \\
\qquad(\mathrm{n}=14)\end{array}$} & \multirow[t]{2}{*}{$t$} \\
\hline & $\mathrm{M}$ & (SD) & M & (SD) & \\
\hline Depression & 19.71 & $(8.15)$ & 15.14 & (8.01) & $2.17^{*}$ \\
\hline
\end{tabular}

By using the pretest depression levels of the two groups as covariates, ANCOVA was carried out for the posttest levels, the result of which can be seen in Table 3. The outcome indicated that a statistically significant difference does exist $(\mathrm{F}=29.74, \mathrm{p}<.001)$ for the posttest depression level.

When looking at the pretest-posttest depression level difference of the experimental group and the control group, a significant decline in depression $(\mathrm{t}=5.57, \mathrm{p}<.001)$ was recorded for the experimental group $(\mathrm{M}$ pretest $=19.71$, $\mathrm{M}$ posttest $=13.00)$. However, an increase in the score was observed for the control group ( $\mathrm{M}$ pretest $=15.14, \mathrm{M}$ posttest $=$ 16.00), which showed no significant difference. Through figure 1 , we can see that sandplay 
Journal of Symbols \& Sandplay Therapy, Vol.7 No.2.

Table 3. ANCOVA between groups for depression

\begin{tabular}{cccccc}
\hline & Source & Sum of squares & df & Mean squares & $F$ \\
\hline \multirow{3}{*}{ Depression } & Covariate & 1066.28 & 1 & 1066.28 & $112.14^{* * *}$ \\
& Between groups & 282.77 & 1 & 282.77 & $29.74^{* * *}$ \\
& Error & 237.72 & 25 & 9.51 & \\
& Total & 7254.00 & 28 & & \\
& Corrected total & 1367.00 & 27 & & \\
\hline
\end{tabular}

${ }^{* * *} p<.001$

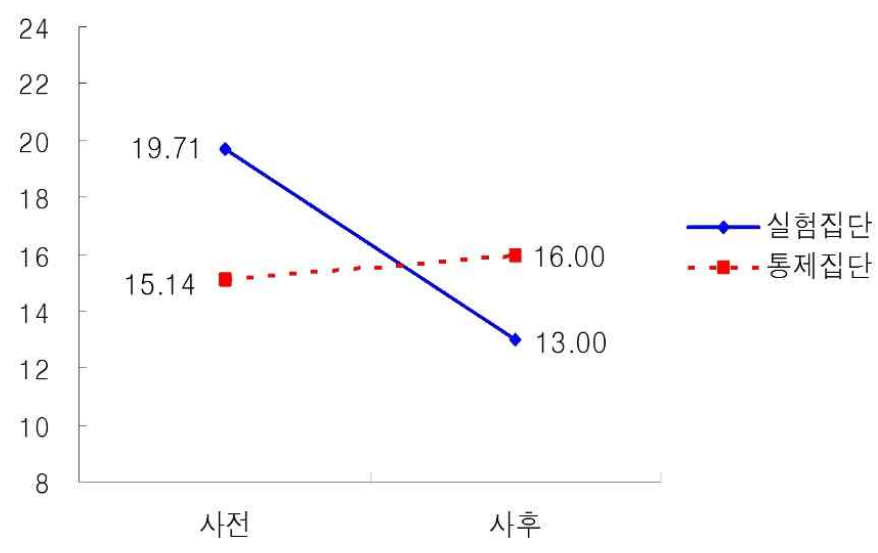

Figure 1. Pretest-posttest changes in the depression level

therapy reduced depression in mothers with disabled children.

2. Can Sandplay Therapy Reduce Parenting Stress in Mothers with Disabled Children?

This study conducted a homogeneity test of the pretest parenting stress level of the experimental group and the control group in order to answer the second research question: "Can sandplay therapy reduce parenting stress in mothers with disabled children?" The outcome of the test is outlined in Table 4.

Among stressor sources, the experimental group's pretest parental distress score $(\mathrm{M}=$ 37.79) was higher than that of the control group ( $M=30.57)$, in which there was a 
Table 4. Homogeneity test: pretest parenting stress level of the experimental group and the control group

\begin{tabular}{|c|c|c|c|c|c|}
\hline & \multicolumn{2}{|c|}{$\begin{array}{l}\text { Experimental group } \\
\qquad(\mathrm{n}=14)\end{array}$} & \multicolumn{2}{|c|}{$\begin{array}{l}\text { Control group } \\
\qquad(\mathrm{n}=14)\end{array}$} & \multirow[t]{2}{*}{$t$} \\
\hline & M & (SD) & M & (SD) & \\
\hline Parental distress & 37.79 & $(7.09)$ & 30.57 & $(4.83)$ & $3.15^{* *}$ \\
\hline Dysfunctional parent-child interaction & 33.43 & $(5.69)$ & 34.36 & $(6.10)$ & -.42 \\
\hline Difficult child & 28.36 & $(7.87)$ & 30.64 & $(5.60)$ & -.89 \\
\hline Total & 99.57 & (12.99) & 95.57 & $(10.78)$ & .89 \\
\hline
\end{tabular}

statistically significant difference $(\mathrm{t}=3.15, \mathrm{p}<.01)$. In other words, there was a different in the pretest parental distress level between the experimental group and the control group. There was no significant difference between the two groups in terms of their dysfunctional parent-child interaction pretest scores and difficult child pretest scores.

The study then went on to evaluate the posttest scores of each stressor source. First ANCOVA was conducted with the pretest parental distress scores of both groups as covariates, the result of which is shown in Table 5. As can be seen in the table, there was a statistically significant difference between the groups $(\mathrm{F}=15.22, \mathrm{p}<.01)$. It can therefore be said that sandplay therapy reduced the pain caused by child rearing in mother of disabled children.

Second is the dysfunctional parent-child interaction. After setting the pretest dysfunctional parent-child interactions scores of both groups as covariates, ANCOVA was conducted on the posttest scores. As seen from the fact that there was a statistically significant difference between the two groups $(\mathrm{F}=34.08, \mathrm{p}<.001)$, it can be said that sandplay therapy reduced the stress caused by dysfunctional parent-child interaction in mother of disabled children.

Third is the difficult child stressor source. Again ANCOVA was carried out on the posttest results by treating the pretest scores of both groups in this domain. There was a significant difference $(\mathrm{F}=9.66, \mathrm{p}<.01)$ between the two groups, which means that sandplay therapy helped reduce the stress caused by the child's difficult temperament. 
Journal of Symbols \& Sandplay Therapy, Vol.7 No.2.

Table 5. ANCOVA between groups for parenting stress

\begin{tabular}{|c|c|c|c|c|c|}
\hline & Source & Sum of squares & $d f$ & Mean squares & $F$ \\
\hline \multirow{5}{*}{$\begin{array}{c}\text { Parental } \\
\text { distress }\end{array}$} & Covariate & 605.10 & 1 & 605.10 & $34.71^{* * *}$ \\
\hline & Between groups & 265.39 & 1 & 265.39 & $15.22^{* *}$ \\
\hline & Error & 435.83 & 25 & 17.43 & \\
\hline & Total & 27779.00 & 28 & & \\
\hline & Corrected total & 1056.68 & 27 & & \\
\hline \multirow{5}{*}{$\begin{array}{l}\text { Dysfunctional } \\
\text { parent-child } \\
\text { interaction }\end{array}$} & Covariate & 781.83 & 1 & 781.83 & $178.23^{* * *}$ \\
\hline & Between groups & 149.50 & 1 & 149.50 & $34.08^{* * *}$ \\
\hline & Error & 109.67 & 25 & 4.39 & \\
\hline & Total & 30225.00 & 28 & & \\
\hline & Corrected total & 1103.25 & 27 & & \\
\hline \multirow{5}{*}{ Difficult child } & Covariate & 991.66 & 1 & 991.66 & $119.61^{* * *}$ \\
\hline & Between groups & 80.08 & 1 & 80.08 & $9.66^{* *}$ \\
\hline & Error & 207.27 & 25 & 8.29 & \\
\hline & Total & 24325.00 & 28 & & \\
\hline & Corrected total & 1410.68 & 27 & & \\
\hline \multirow{5}{*}{ Total } & Covariate & 3711.15 & 1 & 3711.15 & $74.44^{* * *}$ \\
\hline & Between groups & 1850.80 & 1 & 1850.80 & $37.12^{* * * *}$ \\
\hline & Error & 1246.35 & 25 & 49.85 & \\
\hline & Total & 241757.00 & 28 & & \\
\hline & Corrected total & 6051.25 & 27 & & \\
\hline
\end{tabular}

Lastly, the total score of parenting stress was analyzed by conducting ANCOVA for posttest scores, with the pretest parenting stress score as a covariate, the outcome of which is also displayed in Table 5. There was a statistically significant difference between the two groups $(\mathrm{F}=37.12, \mathrm{p}<.001)$ in terms of the posttest total score, which means that sandplay therapy helped reduce the parenting stress in mothers with disabled children (Figure 2). In case of the experimental group, the mean score experienced a significant decrease in parenting stress 
score $(t=7.48, \mathrm{p}<.001)$ after sandplay, from a pretest mean of 99.57 to a posttest mean of 85.50. As for the control group, the pretest mean was 95.57 and posttest mean 98.00, indicating no significant change.

These results suggest that sandplay therapy is effective in reducing stress that stem from parental distress, dysfunctional parent-child interaction, and difficult child.

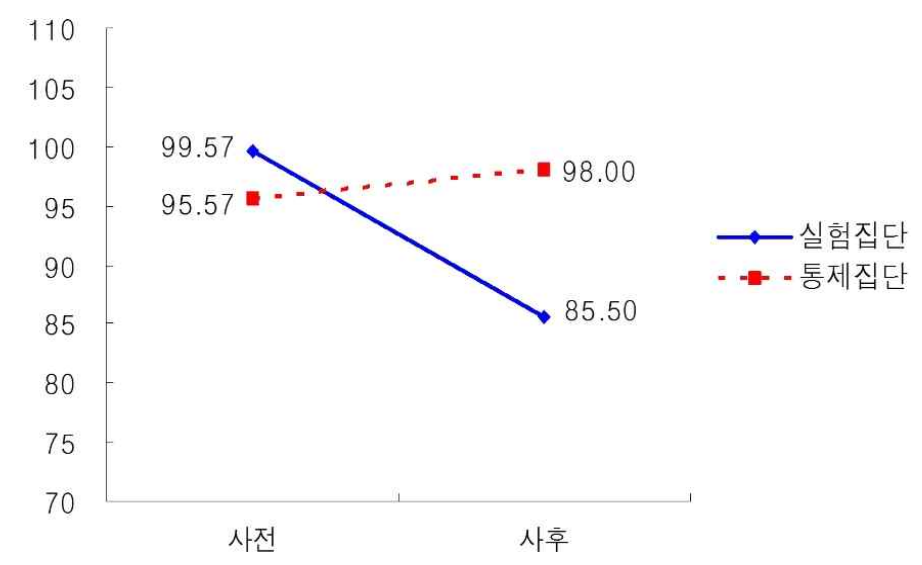

Figure 2. Pretest-posttest changes in the parenting stress level

\section{Discussions and suggestions}

The purpose of this study was to investigate the effect of sandplay therapy in reducing depression and parenting stress in mothers of disabled children. The results obtained in this study are as follows:

First, in order to examine whether sandplay therapy is effective in reducing depression in mothers of disabled children, a homogeneity test of the pretest depression level for both the experimental group and the control group was carried out. The result indicated that the pretest depression levels of the experimental group and the control group were not homogeneous. And then by using the pretest depression levels of the two groups as covariates, ANCOVA was carried out for the posttest levels. When looking at the pretest-posttest depression level difference of the experimental group and the control group, a significant decline in depression 
Journal of Symbols \& Sandplay Therapy, Vol.7 No.2.

was recorded for the experimental group whereas an increase in the score was observed for the control group. There was no significant difference. These findings let us know that sandplay therapy is effective in reducing depression in mothers of disabled children. The results of this study are consistent with the study of Kim (2014), which explained that sandplay therapy can promote ego-differentiation and reduce depression in mothers of disabled adolescent children as well as improve mother-child relationship. It is also in sync with the study of Seo (2014) that sandplay therapy can reduce depression in adults with unstable attachment relationship. Through sandplay therapy, mothers of disabled child became aware of and explored the depression in their unconscious. Realizing that they have become helpless and deprived of energy, they were determined to take care of their inner world, which was expressed in the sandtray. Through the journey in the sand, they discovered their inner potential to integrate the conscious and the unconscious and to resolve the depression.

Second, to see whether sandplay therapy is effective in parenting stress in mothers of disabled children, a homogeneity test of the pretest parenting stress level for both the experimental group and the control group was conducted. What we found was that among the parenting stressor sources, no significant difference was observed in the dysfunctional parent-child interaction, difficult child and total score domains. But there was a significant difference in the parental distress domain. By using the pretest results as covariates, ANCOVA was carried out for the posttest levels. Even for the parenting stress total scores, the score of the experimental group experienced a significant reduction whereas that of the control group experienced an increase; there was a significant difference between the two. These results informed us that sandplay therapy is effective in reducing parenting stress-stemming from three major stressor sources, the parental distress, dysfunctional parent-child interaction, and difficult child-for mothers of disabled children. These findings are consistent with the study of Park (2008) and Han (2009), both of which found that sandplay therapy help reduce the parenting stress score of mothers of disabled children. They are also in tune with the study of Kim (2012) which elaborates that sandplay therapy reduces parenting stress and the salivary cortisol level in mothers whose children attend counseling centers and promotes stress-coping mechanisms. Sandplay therapy enabled mothers of disabled children to express their repressed 
needs and conflicts, thereby bringing balance and integration. Mothers found the energy to cope of parenting stress through this deep inner work.

The purpose of this study was to examine whether sandplay therapy reduces depression and parenting stress in mothers of disabled children. The results speak that sandplay therapy indeed is effective in reducing depression and parenting stress in mothers of disabled children. This study is expected to provide basic data that can be utilized as a psychological therapeutic approach for seeking the stability of depressed ego-resulting from depression and stress-in mothers with disabled children, and for improving quality of care for disabled children.

Finally, based on the results obtained in this study, we would like to point out some limitations of the study and make suggestions for future researches.

First, there is a difference in the gender, age, and type and degree of disability among the participants, which means that the level of stress among the mothers will differ as well. Therefore it is difficult to generalize the results of this study. Future studies would have to select participants more carefully based on their gender, age, type and degree of disability, and whether the disability is congenital or acquired.

Second, it is necessary to create a quiet therapy environment in which the participants can fully concentrate on sandplay therapy. The therapy room provided for this study was not soundproof, and the researchers could see that sounds from outside made the participants anxious. Some participants complained that the therapy environment disturbed them from doing the process. Because sandplay therapy is a process through which clients reveal their inner stories, we should make sure to provide an environment that does not distract them in any way from focusing on the work.

Third, this study was not conducted in a single therapy room. The location of the figure shelf and other components of the therapy room was different for the participants. Plus, there was not a great range of figures available, which limited what the participants could express in the sand. Related studies in the future would have to be conducted in the same therapy room for all clients, with a diverse selection of figures.

Despite these limitations, this study is meaningful as it attempted to accommodate the difficulties in mothers of disabled children and, through the medium of sand and symbols, 
Journal of Symbols \& Sandplay Therapy, Vol.7 No.2.

provided a new stimulus as well as protective, accepting environment where the mothers were free to express their depressed feelings and emotions. By doing so, the study showed that sandplay therapy is effective in reducing depression and parenting stress experienced by mothers of disabled children.

\section{References}

Abidin, R. R. (1983). Parenting stress index-manual (2nd ed.). Charlottersville, VA: Pediatric Psychology Press.

Baek, J. (2009). Parenting behavior in depressed and nondepressed mothers and children's behavior problems: Focusing on perception of mother and child. Doctoral dissertation, Ewha Womans University.

Beck, A. T. (1976). Cognitive therapy and the emotional disorders. NY: International Universities Press.

Choi, H. (2007). A study on parenting stress in mothers of children with cerebral palsy and the children's social ability: An analysis on the moderating effect of family resilience. Master's thesis, Yonsei University.

Han, G. (2009). Effects of a sand tray for self-growth on parenting stress of mothers with disabled children. Master's thesis, Daegu University.

Hong, Y., \& Kim, J. (2003). Depression in mother with disabled children and spouse support. Yonsei Social Welfare Review, 9, 211-230.

Jeon, H. (2006). The effects of a parent-to-parent program on parenting stress, parental efficacy, and family empowerment in mothers of children with disabilities. Doctoral dissertation, Ewha Womans University.

Jeong, J. (2008). Parent efficacy and parenting stress in mothers of children with developmental disabilities through group art therapy - A study on self conception. Master's thesis, Hanyang University.

Jeong, H., \& Kim, S. (2010). A study of effect that economic stress and depression have on 
child neglect in developmental disability children's mothers - The moderating effects of social support. Journal of Emotional \& Behavioral Disorders, 26(3), 257-275.

Kim, K., \& Kim, K (2010). A case study of cognitive behavioral family art therapy to reduce child's anxiety and mother's parenting stress and depression. Korean Journal of Art Therapy, 17, 229-255.

Kim, S. (2014). The effects of sandplay therapy on improving the self-differentiation, depression, and mother-child relationship of mothers with teenage children. Journal of Symbols \& Sandplay Therapy, 5(1), 1-12.

Kim, Y. (2012). Effects of a sandplay therapy on parenting stress, way of coping with stress and salivary cortisol levels of parents with children receiving counseling at a child counseling center. Master's thesis, Namseoul University.

Kim, J. (2011). Family leisure activities and parenting stress of parents of the disabled cbildren. Master's thesis, Kangwon University.

Lee, C. (2008). A study on the degree of parenting stress and coping style of mothers with mentally disabled cbildren in middle school. Master's thesis, Dankook University.

Lim, H. (2004). The effect of social support on parenting stress and depression in mothers with disabled children. Korean Journal of Social Welfare, 1, 653-670.

Lee, J. (2008). A study of parenting stress and coping strategies in mothers of cbildren with brain lesion. Master's thesis, Kongju National University.

Lee, K. (2008). The effect of social support network and support level on the parenting stress and depression in mothers of disabled children. Korean Journal of Family Welfare, 13(1), 43-61.

Lee, S. (2000). Relationship between stress and depression in mothers of mentally disabled children and social support. Master's thesis, Daejeon University.

Lee, S. (2005). The relationship between parenting stress and psychological well-being in mothers with developmentally disabled children: The mediating effects of aggressive coping style and social support. Doctoral dissertation, Chonnam National University.

Lee, Y., \& Hwang, S. (2015). A study of factors which influence the compassion fatigue, compassion satisfaction and parenting sense of competence of mother of children with 
Journal of Symbols \& Sandplay Therapy, Vol.7 No.2.

disabilities. Journal of Emotional \& Behavioral Disorders, 31(3), 485-506

Lee, Y., \& Song, J. (1991). A study of the reliability and the validity of the BDI, SDS, and MMPI-D scales. The Korean Journal of Clinical Psychology, 10(1), 98-113.

Ministry of Health and Welfare (2015). Guides to the evaluation of degree of disability. Seoul: Ministry of Health and Welfare.

Park, S. (2008). The effects of the sand play therapy on parenting stress of the mothers of developmental disability children. Master's thesis, Daegu University.

Seo, H. (1992). A study on the adaptation of mothers with disabled children and social support. Master's thesis, Yonsei University.

Seo, M., Jang, E., Jeong, C., \& Choi, S. (2003). The study of the parenting stress, depression and parenting efficacy on the mother of attention deficit hyperactivity disorder children. The Korean Journal of Clinical Psychology, 8(1), 69-81.

Seo, Y. (2014). Influence of sand tray play on emotional regulation ability: An insecure adult attachment mother's case study. Master's thesis, Daegu University.

Shim, J. (1994). Sandplay therapy. Seoul: Yangyounggak.

Shin, J. (2006). The effect of sandplay therapy on parental stress. Master's thesis, Ajou University.

Received : October 30, 2016

Revised : December 1, 2016

Accepted : December 1, 2016 